\title{
A Counseling Case on Problems of College Students' Interpersonal Communication
}

\author{
Jingjing Liu ${ }^{1}$ \\ ${ }^{1}$ Yancheng Teachers University, Yancheng, China \\ Correspondence: Jingjing Liu, Dushiyihao 10\#301, Tinghu, Yancheng City, Jiangsu Province, China. Tel: \\ 86-136-2621-9516. E-mail: $30098890 @ q q . c o m$
}

Received: August 16, 2018

Accepted: February 2, 2019

Online Published: April 29, 2019

doi:10.5539/ies.v12n5p28

URL: https://doi.org/10.5539/ies.v12n5p28

\begin{abstract}
In allusion to psychological problems caused by interpersonal communication, counsel with the theory of humanism, cognitive therapy, and the methods related, to help the visitor exploit potentialities and positive resources contains in herself, rectify unreasonable believes at the same time, increase the confidence and courage to changes in interpersonal relationships, challenges, setbacks, construct a reasonable mode of interpersonal communication, promote the growth and perfect of the personality. Through 5 consultations, the target was basically achieved.
\end{abstract}

Keywords: interpersonal communication, unreasonable believes, college student

\section{Introduction}

Interpersonal communication is important to college students, for they can make information exchange, make friends, get emotional support, know each other better, etc. Many researches have been carried out on college students' interpersonal communication. The application of new social software enriches the forms and ways of interpersonal communication. However, with the increasing dependence on mobile phones, the traditional face-to-face communication is rather strange and difficult for the new generation. Since the importance of the interpersonal communication has been widely accepted by people, more and more researchers have focused on the specific communicating skills, the application of interpersonal communication in specific fields, cross-cultural (Kim \& McKay-Semmler, 2013), medical field (Baelden, Audenhove, \& Vergnani, 2012), teaching (Rodriguez-Lopez, Souto, \& Arroyo-Noblejas, 2014). From the views of psychology, improve the anxiety with means of group guidance (Zhao, 2011), the tendency of the interpersonal perceptions by depressed college students (Hokanson, 1991). According to a review of cognitive behavioral theory, the birth of cognitive behavioral psychotherapy (CBT) approaches has often been described as the clinical equivalent of the cognitive revolution which took place in the field of scientific psychology. The revolution consisted of the addition of a cognitive mediator interposed between environmental triggers and behavioral responses (Ruggiero et al., 2018). Some individuals are more likely than others to be exposed to negative environmental stimuli, less likely to be exposed to positive stimuli, or more likely to attend preferentially to negative information. In the contexts of stress, these individuals are more likely to experience distress and less likely to engage the kinds of reappraisal and coping strategies that would produce naturalistic recovery. Cognitive and behavioral therapies represent an attempt to activate these resources (Lorenzo-Luaces, Keefe, \& DeRubeis, 2016).This research used the cognitive-behavioral therapy and skills related to help the student walk out of the dilemma of interpersonal communication.

\subsection{General Information}

One college student with emotional problems in interpersonal communications will have a negative impact on her study and daily life. Take the time and influence degree into consideration, the counsel use cognitive therapy and methods related to push the visitor realize her misconception, find suitable communication skills, help her set up confidence in interpersonal communication.

\subsubsection{Demographic Information}

Lin, female, 20 years old, freshman. 


\subsubsection{Personal Growth History}

Came from rural area of Shandong Province, has a younger sister, Parents work in the country town near the old house, being a board student from high school. No physical disease, no mental illness and no family genetic disease. A rural student comes from poor family.

\section{Main and Personal Statements}

The main statement was unable to listen attentively in class and came to the school psychological counseling center for consulting with strong motivation.

Personal statements: Could not concentrate in class and once answered wrong in specialized course, felt the teacher disappointed, afterwards, in this course, couldn't look into the teacher's eyes, always kept head down in class, felt the teacher also dodging herself, thinking that the teacher didn't like her, so didn't want to see the teacher any more, but considering the course would continue, the teacher would take the course for the next school year, the visitor felt even worse. In fact, from primary school to university, her preference for teachers, the situation in class used to be the same, feeling that all the head teachers did not like her, once could not answer questions or similar situations happened, there would be similar psychological shadow, psychological sense of loss, and angry towards the teacher. This time, the emotions and feelings lasted for 2 weeks, and this course was twice a week. Meanwhile the interpersonal relationship in the dormitory was not harmonious and there were contradictions, made her depression and irritability even worse. The physical and mental state of the visitor was good, with normal in appetite and sleep, occasional physical exercise, but serious emotional disturbance, poor mood, lonely emotional feeling, no serious disease, no suicide and self-harm thoughts or behaviors.

\section{Consultant's Observation}

The visitor was neatly dressed, well described, well built, with wobbly feet, incessant hand-rubbing, showing nervous mood. The consultant helped the visitor release tension by explaining the confidentiality principle and doing relaxation exercises.

\section{Assess and Diagnose}

\subsection{Initial diagnosis}

General psychological problems.

\subsection{Diagnostic Basis}

Once failed to answer the teacher's questions in class, she has emotional problems, which affected her attitude towards the teacher and further affect her attention in class. For 2 weeks, the negative emotions were not generalized and her social functions had not been affected, so diagnosed this case as general psychological problems.

\subsection{Differential Diagnosis}

According to three principles of disease and non-disease (Guo, 2005), the subject world and the objective world are unified, the inner consistency of mental activities, the relative stability of personality, mental psychological disorders can be excluded, as the self-knowledge of the visitor was normal, her emotional problems was based on specific practical problems, and the duration within a month.

\section{Reason Analysis}

The visitor cannot rationally analyze the frustrating event of failing to answer the teacher's questions, with false beliefs, deep frustration and avoidance of teachers. With the habit of thinking in childhood continued, she connected the inability to answer question in class one time to the teacher's evaluation of her whole, thought teachers tended to look down on her because of that, misunderstood the teacher, denied herself, and at the same time lost the enthusiasm and interest towards the course. The visitors' negative thinking habit in childhood did not change with age. It is easy to generalize the similar situation due to similar setbacks, which can be extended to negate one. The underlying reason behind the negative thinking habit is low self-evaluation and low confidence. According to the cognitive behavior theory, problems are the result of maladaptive thoughts. The cognitive therapist assists the client to reinterpret events in a more adaptive manner through conscious processes of recognizing, challenging, and restructuring thinking (Early \& Grady, 2017). The inner mental process of the visitor's problems is listed in Figure 1. 


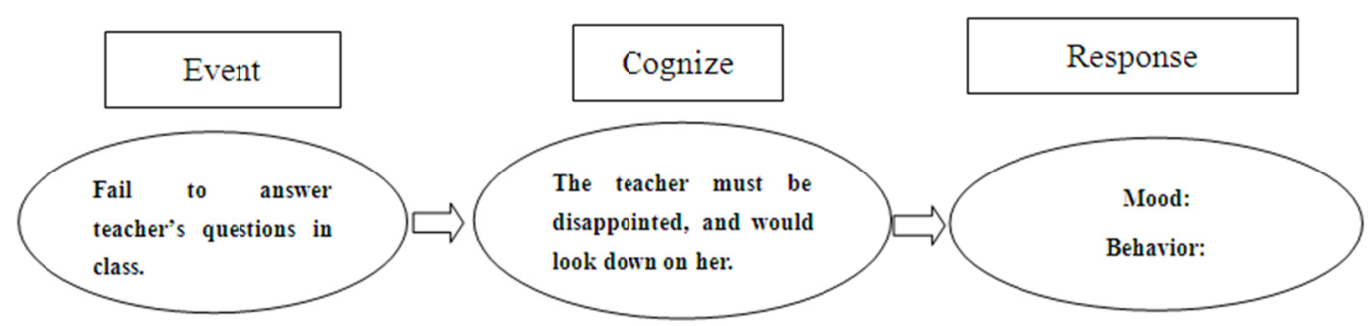

Figure 1. The inner mental process of the visitor's problems

Mood: Long-term frustration, with anger towards the teacher.

Behavior: Avoidance, avoid the teacher, avoid the corresponding curriculum, as lose the bravery to face the teacher - one way of self-preservation, usually adopted in childhood, and people with negative self-views may use it even in their adulthood.

\section{Consulting Goal Setting}

\subsection{Short Term Goal}

Help the visitor develop a reasonable way of attribution, make the visitor explain the frustrated event more reasonably. It was common for teachers to ask questions and students can't answer them. It was also an opportunity for the students to know what they didn't master, so they could adjust their learning methods. For the problem of interpersonal relationship in the dormitory, discuss with the visitor according to the principle of one problem at a time, and discuss it after the trouble of the relationship between teachers and students is solved.

\subsection{Stage Goal}

Help the visitor to explore appropriate interpersonal skills, and use them to get along well with teachers, roommates and friends, enhance the courage to face changes and setbacks in communication, and build confidence in interpersonal communication.

\subsection{The Ultimate Goal}

The positive resources of the visitor can be mined to affirm the value of the visitor, so that the visitor can build up confidence in herself. In interpersonal communication, when encountering setbacks or being rejected or criticized, the visitor can form a habit of thinking aims to solve problems instead of indulging in negative thinking, generalized to other relationship.

\section{Counseling Process}

\subsection{Consulting Programs and Principles}

Based on principles of humanism, affirm the visitor's positive intention to solve the current problems of interpersonal relationship, establish good peer relationship and student-teacher relationship, show empathy and understanding towards the visitor's worry and sad mood, using the Beck cognitive therapy, explore the misconception hidden in the thinking habit, which influence her interpersonal relationship, with the skills of role play, decentering, Socrates dialogue. Beck\& Raimy's cognitive therapy (CT), a cognitive behavioral therapy founded by Alan t. Beck and v. c. Raimy, emphasizes the dual role of a consultant as a diagnostician and an educator. It is a kind of short-range psychological treatment, identifying the problem by establishing counseling relationship, counseling goal, questioning and self-audit technical, examine surface misconceptions through suggestions, demonstration and imitation, correct the core misconceptions with semantic analysis technology, further cognitive change, consolidate the new ideas of ways to help visitors to change bad understanding, to eliminate negative emotion and behavior.

\subsection{The Rights, Responsibilities and Obligations of Both Sides}

The consultant takes the initiative to inform the visitor of the principles, functions and limitations of psychological counseling, emphasizes the confidentiality and confidentiality exception principle, and emphasizes the strong power of the client's self-improvement. The visitor be asked to explain the event situation and feelings honestly and truthfully, abide by the relevant agreement, complete the assigned homework.

\subsection{Time and Cost of Consultation}

Once a week, 50-60 minutes each time. Individual psychological counseling in the school psychological 
counseling room, free of charge.

The consultation process lasted five times. It was divided into diagnosis stage, consultation stage and consolidation stage.

\section{The Counseling Process}

\subsection{1 st Consultation}

\subsubsection{Present Problems}

Unable to look at the teacher, the visitor felt upset and couldn't concentrate on the class, at the same time have the dormitory interpersonal conflict problems. Multiple interpersonal problems add up to aggravate negative emotional experience.

\subsubsection{Decide the Objectives and Plans of the Consultation Through Negotiation}

On the basis of collecting the visitor's personal basic information, personal growth experience, listening to the visitors about her problems, discussed the psychological consultation plan and target. Aims to change her unreasonable faith, establish reasonable attribution ways, reasonable skills to deal with interpersonal relationship through psychological counseling, enhance the visitor's confidence and courage, thus improve her self-evaluation level.

\subsubsection{The Counseling Process}

Through the techniques of empathy, questioning and self-review, the visitor reviewed the event and its impact on her, and found the illogical belief in her own cognitive process. The visitor thought that only if she answered the questions in class correctly could she be accepted by the teacher, once failed, felt ashamed that she lose face in the class. Use empathy and interpretation, couldn't answer the teachers' questions in class surely make students feel ashamed, it was normal, as most students hoped to get the teacher's appreciation and praise naturally, make a good image in front of the teacher and the peers. "Have you ever seen others failing to answer teachers' questions in class? What were their reactions and attitudes?" "How did the teacher react when students couldn't answer questions correctly?" "When encountering the same problem, what's the difference in the teachers' attitude towards you and other students?" "If you were the teacher, how would you react?" Raised questions about the issue, to evoke self-censorship from the visitor, helped her review her attitude, emotion, including resentment, hostile, avoidance, towards frustrating events. Guide the visitor find out more reasonable cognitive attribution and methods to handle negative events, can take the classes normally after reconstructing her cognition.

Homework: Run 20 minutes every night to relax.

\subsection{2nd Consultation}

\subsubsection{Presenting Problems}

The visitor said she could face the teacher, attend class normally after the first consultation. She wanted to talk about her dormitory relations this time. She couldn't get along well with her roommates. The roommates said her feet smelled bad. She felt rejected by them, and felt very lonely. She was afraid of being rejected. However, when there was garbage in the dormitory, it was always her took them out. She felt that they detest her and deliberately gave the dirty work to her. One roommate has a relatively good relationship with the visitor, and another one always dressed in fashionable clothes. Girls in the dormitory did not ask the fashion girl to do things. She envied the fashion girl's treatment, feeling that she was excluded by others. Due to lack of confidence, she dare not communicate with others, and fear of being isolated and avoiding conflicts, the mood and feeling last for over six months.

\subsubsection{The Counseling Process}

The counselor affirmed the visitors' willingness and efforts to improve relationships in the dormitory. "How to deal with the foot odor?" "I can take measures to keep feet dry and clean, especially after sports." "How do you handle disagreement in the dormitory normally?" "Talk with them less frequently then can avoid conflict or unhappiness." "What is the effect of this method?" "What else can we do if avoidance doesn't solve the problem?" Guide her present her cognitive patterns and attribution habits gradually, reviewing the actual effects, then change negative attitude into positive actively. Encourage her express thinking and emotions in communication with roommates. The visitor thought she was not excellent, and the roommates despised her and was not treated with respect and fairness, but if she refused their demands, the interpersonal relationship would become worse and she was afraid of being isolated. The psychological counselor described several events, find out more reasonable communicational methods with the visitor, used the role playing skills to simulate a similar scenario in the dorm, consultant played 
as one roommate, the visitor use new ways to cope with, then switch roles. The visitor could experience different feelings that different attitudes and skills bring to relationships. Train the visitor to seek more appropriate coping skills actively, including how to express her real thoughts and how to refuse others. By reviewing the changes of interpersonal relations in her past, she realize that interpersonal communication was not fixed, and mastering appropriate communication skills could make others understand and accept her, she herself had the ability to explore useful methods. It's impossible to build normal relationships by simply suppressing your thoughts and avoiding conflict.

\subsection{3rd Consultation}

\subsubsection{Presenting Problems}

After last counseling, she tried to communicate with one roommate to build a good relationship, but was rejected. Another roommate lost her temper to the visitor due to physical condition, she felt a little depressed.

\subsubsection{The Counseling Process}

Psychological test the visitor did by herself showed interpersonal tensions. The only one friend leaved in another dormitory, the visitor once told her about the distress, the friend said there was nothing wrong, her problem was lied in she thought too much nonsense. The visitor felt disappointed, as she didn't get empathic response and emotional support from her friend. Very tired of herself emotional state, insisted that the extrovert didn't like the introvert, once on the Introductory Lecture, the visitor was too exaggerated, did not get even one vote, even those familiar classmates did not vote on her, so felt very hurt. Besides, learning state was normal, unaffected, and sleeping was normal as well. Correct her unreasonable belief: "extroverts don't like introverts.

Discussed with the visitor, and acknowledged the advantage of the extroverts. Extroverts were willing to communicate with others, be more lively, actively, and easier to integrate into the group. However, introverts were quiet, calm, and a good listener, who could also be welcomed. Through simulation scenarios, made the visitor experience the feelings her over exaggerated self-introduction to others. So she could realize only truthful, sincere but not unrealistic statement can win respect and acceptation from others. And be frank and honest towards one's own advantages and disadvantages was also a good merit. We could make friends based on a better understanding to each other through our daily communication. But if the requirements from others were beyond her ability or unfair; she could refuse politely. Accept others' all requirements blindly, regardless real thinking and feelings of one's own was not a reasonable way to make friends, it usually let others think you can meet all their requirements, and they might ask for more. Explore effective communication methods based on her life experience, treat others with mutual respect, empathy, how and when to say no, etc.

Homework: Consider the principles and bottom line of her own in interpersonal communication. Exercise to express her true feelings to dorm mates with the communication skills she had learned.

\subsection{4th Consultation}

\subsubsection{Presenting Problems}

Recently one classmate wanted to make friends with her only good friend. The visitor felt the good friend would be robbed by others. She felt the loneliness of being deprived and abandoned.

\subsubsection{The Counseling Process}

After last counseling, she communicated with roommates frankly, although they changed little in the attitude, she herself felt a bit better. Another classmate recently showed intimate association with her only friend, she seemed to rob her own good friend, so she felt badly and feared be abandoned by the friend and loss the friendship. She felt strong possessive possession in herself, but thought it was also nice to play several girls together, had communicated with close friends before, hoped her not be cold to her because of new friend. The visitor felt some unfair in the heart, because the friend was the only one to her, but she soon made new friends. She turned to the Internet for similar examples, but the commentaries all said that the protagonist was selfish, possessive. Felt bad and upset to think about that, didn't know what to do, wanted to cry. The friendship was unique to her, so the visitor's anxiety was more serious than before, when her teacher-student relationship encountered problems. The motivation for counseling was more urgent. In consultation, explored with her and lead her discover irrational beliefs, absolutism, generalizations, and terrible thoughts in her thinking. The absolute idea was "she is my only friend, I couldn't have any more." "New friend comes with the old has to gone." "Friends should treat me as the way I treat them." "Life will be horrible if I was abandoned by the friend." Generalizing: "I'm an exclusive, selfish person." Use face quality and other influencing techniques to intervene on her. "What is the reason your friend make new friends with others?" "Will she be the only one friend in your whole life?" "As your friend, whether she 
has the right to make new friends?" "Was your life a mess before you met your current friend?" "Are you always happy when you are with her?" Promote the visitor to rethink her friendship, feelings, beliefs, behavior and the deep understanding of the condition, confess the friendship was not perfect as she thought, and endeavor to find other familiar and friendly girls, construct more friendship with them, and make constructive positive thinking and social activities. At the same time, she has the ability to do that. The establishment of peer relationship is two-way, diversified and constantly changing. Changing is life, she also could benefit from the change.

\subsection{The Fifth Time Consulting}

\subsubsection{Presenting Problems}

Talked with her friend after last counseling, she said that they did not deliberately alienate her, but sometimes it was difficult to agree on the content and time of action. The visitor showed understanding, and gradually accepted the fact that the friend spends less time with her together. Try to make new friends, but don't know how to do, hope to get some inspiration from consulting.

\subsubsection{The Counseling Process}

The visitor was honest with her peers and can accept the fact that her only friend had making new friends, expressed her feelings smoothly and stably means that she could put the burden down. Talked about how she has changed since consulting and felt a little more confident about improving her relationships. The consultant advised her keep optimistic state of mind, find effective communicate skills to get along well with others, construct a positive, confident, open, faithful relationship. The inner mental process after the counseling is listed in Figure 2.

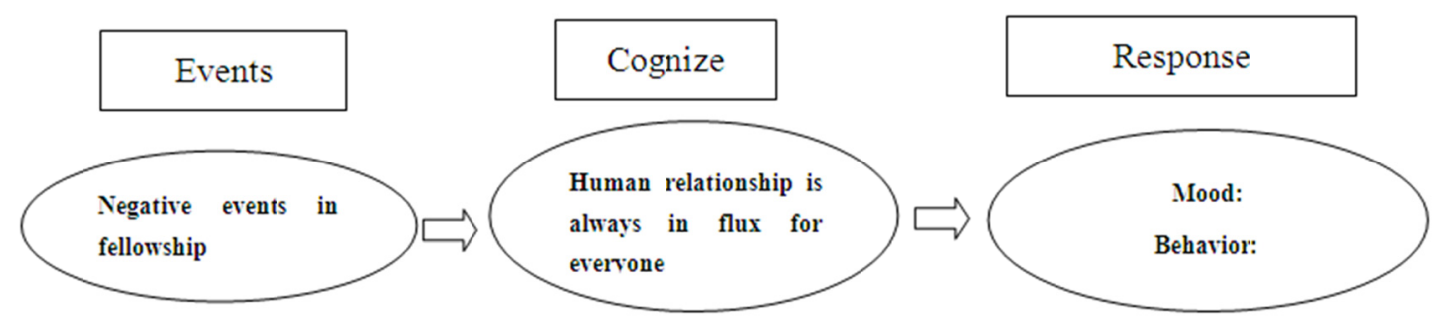

Figure 2. The inner mental process of the visitor towards negative incidents after counseling

Cognize: The original relationship is not $100 \%$ perfect. Both the visitor and her friend should not be blamed. She has the ability to deal with the changes in relationship. She can find out suitable skills to communicate with others by herself.

Response: Mood: calm, no longer resentment against friend and herself, no longer feel depressed by others' subtle actions.

Behavior: could communicate with peers frankly, try to find new friends.

\section{Consultation Summary and Reflection}

Psychological problems caused by interpersonal relationship is widely exist in college students, which may lead to individual mood problems such as depression, anxiety, further influence their study and daily life. In this psychological consultation case, the visitor came to consultation because of the teacher-student relationship and peer relationships, the consultant used cognitive behavioral therapy method, pushing her find emotional and behavioral problems hidden mistake, pessimism, absolute idea, correct her irrational beliefs. Some have been exist in her childhood. Repetitive negative thinking (RNT) is a major risk factor for mood and anxiety disorders, such as "teachers/peers don't like me." "I can't face to teachers if fail to answer their questions in class." The repetitive negative thinking makes the visitor vulnerable to bad mood and anxiety disorders. The yearning for good interpersonal relationships, along with the lack of confidence in interpersonal skills lead to approach-avoidance conflict, influenced her perception of negative events. So the visitor still keeps the cognitive habits in her childhood even if she has entered the university. Afraid of loneliness, longing for stable and lasting friendship, but few friends, so lack of stable emotional support system, be sensitive in interpersonal relationship, vulnerable in emotion. In the preliminary diagnosis, although have noticed the factor of self-esteem, the counselor just helped improve her communication ability as her problems belonged to the general psychological problems. But the visitor has inferiority complex, sensitive and fragile, her interpersonal communication could be influenced by negative event easily, her inferiority tendency is the crux of the problem establish interpersonal self-confidence, so 
the counseling should focus on self-evaluation as early as possible. Enhance the visitor's self-confidence, change her misconception, and turn passive thinking to active, to promote the active thinking about her true idea. Explore communication skills suitable for her with psychological counseling skills. Rebuild support system, enhance the courage and confidence to face the interpersonal problem, and promote her personality growth and perfection.

Interpersonal relationship is important to college students, especially freshman, which definitely influence the academic engagement and well-being of their college life. According to some research, students' perceptions of teacher, parent, and peer relationships were associated with PB goals and the three types of academic engagement: cognitive, behavioral, and emotional engagement. But the skills of interpersonal relationship and cognitive towards setbacks varies tremendously in different individuals, the college should encourage association activity of students and adapt more useful teaching methods to further the communication of teacher-student besides psychology consultant services, and offer interpersonal relationship training program to college students. As the researches have done, in interpersonal relationships shared reality, shared beliefs and values (meaning systems) link the self to close others in memory. Apply the research results to the education management of the school can improve the interpersonal relationship of the youth effectively.

\section{Acknowledgements}

This work is supported by Jiangsu Education Science 13th Five-Year plan 2018(X-a/2018/19).

\section{References}

Baelden, D., Audenhove, L., \& Vergnani, T. (2012). Using new technologies for stimulating interpersonal communication on HIV and AIDS. Telematics and Informatics, 29(2), 166-176. https://doi.org/10.1016/j.tele.2011.05.002

Early, B. P., \& Grady, M. D. (2017). Embracing the Contribution of both Behavioral and Cognitive Theories to Cognitive Behavioral Therapy: Maximizing the Richness. Clinical Social Work Journal, 45(1), 39-48. https://doi.org/10.1007/s10615-016-0590-5

Guo, N. F. (2005). China employment training technology guidance center \& China Mental Health Association. Psychological counselor (level two). Beijing: Nationalities Publishing House.

Guo, N. F. (2005). China employment training technology guidance center \& China Mental Health Association. Psychological counselor (level three). Beijing: Nationalities Publishing House.

Hokanson, J. E., Hummer, J. T., \& Butler, A. C. (1991). Interpersonal perceptions by depressed college students. Cognitive Therapy and Research, 15(6), 443-457. https://doi.org/10.1007/BF01175728

Kim, Y. Y., \& McKay-Semmler, K. (2013). Social engagement and cross-cultural adaptation: An examination of direct- and mediated interpersonal communication activities of educated non-natives in the United States. International Journal of Intercultural Relations, 37(1), 99-112. https://doi.org/10.1016/j.ijintrel.2012.04.015

Lorenzo-Luaces, L., Keefe, J. R., \& DeRubeis, R. J. (2016). Cognitive-Behavioral Therapy: Nature and Relation to Non-Cognitive Behavioral Therapy. Behavior Therapy, 47, 785-803. http://doi.org/10.1016/j.beth.2016.02.012

Rodriguez-Lopez, A., Souto, J. E., \& Arroyo-Noblejas, M. L. (2014). Improving teaching capacity to increase student achievement: The key role of communication competences in Higher Education. Studies in Educational Evaluation, 116, 4983-4987. https://doi.org/10.1016/j.stueduc.2018.10.002

Ruggiero, G. M., Spada, M. M., Caselli, G., \& Sassaroli, S. (2018). A Historical and Theoretical Review of Cognitive Behavioral Therapies: From Structural Self-Knowledge to Functional Processes. Rational-Emotive \& Cognitive-Behavior Therapy, 36, 378-403. http://doi.org/10.1007/s10942-018-0292-8

Zhao, Y. (2011). A Probe into the Intervention of College Students' Anxiety in Interpersonal Communication by Means of Group Guidance. In S. Lin, \& X. Huang (Eds.), Advances in Computer Science, Environment, Ecoinformatics, and Education. CSEE 2011. Communications in Computer and Information Science, 218, 38-42. https://doi.org/10.1007/978-3-642-23357-9_8

\section{Copyrights}

Copyright for this article is retained by the author(s), with first publication rights granted to the journal.

This is an open-access article distributed under the terms and conditions of the Creative Commons Attribution license (http://creativecommons.org/licenses/by/4.0/). 